\title{
A FLEXIBLE AND EXPLANATORY MODEL OF LIGHT DISTRIBUTION AND PHOTOSYNTHESIS IN ROW CROPS
}

\author{
H. GIJZEN ${ }^{1,2}$ and J. GOUDRIAAN ${ }^{2}$ \\ ${ }^{1}$ Centre for Agrobiological Research, P.O. Box 14,6700 AA Wageningen (The Netherlands) \\ ${ }^{2}$ Department of Theoretical Production Ecology, Agricultural University Wageningen, \\ P.O. Box 430, 6700 AK Wageningen (The Netherlands)
}

(Received March 25, 1988; revision accepted February 4, 1989)

\begin{abstract}
Gijzen, H. and Goudriaan, J., 1989. A flexible and explanatory model of light distribution and photosynthesis in row crops. Agric. For. Meteorol., 48: 1-20.

A model for gross photosynthesis of a hedgerow crop was developed. Diffuse and direct light distribution and absorption were calculated by taking account of scattering and reflection. Leaf photosynthesis was calculated from absorbed light and integrated over the row. The model can describe different row geometries, vertical leaf area density distributions and leaf angle distributions. For path widths $<30 \%$ of the row height, simulation results showed that light absorption and crop photosynthesis under diffuse light are little reduced compared with a closed canopy. The effect of the vertical distribution of the leaf area density on row crop photosynthesis was small. The edge effect in a homogeneous field crop was studied as a special geometric situation. Daily totals of row crop photosynthesis were found by integration over the diurnal curve and were calculated for different latitudes.
\end{abstract}

\section{INTRODUCTION}

In most crop growth models, light penetration and absorption are calculated in horizontally homogeneous canopies to assess the rate of crop photosynthesis or the efficiency of conversion of intercepted light into dry matter. The assumption that the crop is horizontally homogeneous may cause large errors in estimating crop growth when individual plant canopies are arranged in distinct rows, e.g., in orchards or during early growth of a crop. This situation occurs particularly in greenhouse crops because they require ready access during the early growth and production stage.

Most models for crop photosynthesis which account for row structure concentrate on the relative amount of light that is intercepted. Some of these models assume the row cross-section to be ellipsoidal (Charles-Edwards and Thorpe, 1976) or an array of ellipsoidal sub-canopies randomly distributed in 
the row (Mann et al., 1980; Whitfield, 1986). Others assume a triangular or rectangular cross-section of the rows (Allen, Jr., 1974; Rabbinge, 1976; Goudriaan, 1977; Palmer, 1977; Jackson and Palmer, 1979; Mutsaers, 1980).

The distribution of light in row crops was calculated by Goudriaan (1977), Acock et al. (1978) and Jackson and Palmer (1981), considering only a few of the aspects of light penetration into a canopy. Norman and Welles (1983) developed a general and extensive model for the penetration of radiation in individual ellipsoidal plant canopies that can be variously spaced.

The present study is primarily intended for application to greenhouse row crops. In greenhouses, optimization of the environment for crop growth and development is possible and can be based on (among others) continuous assessment of the rate of crop photosynthesis.

Present row models have limited applicability for this application, as usually they do not handle the following aspects of light penetration in a row crop: distribution of diffuse and direct light, reflection, multiple scattering and absorption by leaves. In other cases, the models are too cumbersome and computations too numerous for practical application in dynamic control of the greenhouse climate.

Therefore, in this study, a model was developed that calculates the distribution and absorption of direct and diffuse light, reflection and multiple scattering with relatively simple computational schemes. Since only visible radiation is important for photosynthesis, a short cut was possible by using existing equations for multiple scattering in horizontally homogeneous canopies. The equations were used inside the rows, but interactions between rows were neglected. Calculation of radiation absorbed by the leaves provided a direct connection with leaf photosynthesis. Spatial integration of leaf photosynthesis was performed to obtain canopy photosynthesis. A hedgerow configuration was chosen to describe the most significant clumping pattern of leaves in most row crop canopies and to avoid complicated geometrical calculations. Various crop characteristics such as vertical leaf area density distribution, leaf angle distribution and row geometry can be accounted for by the model, so that a large variety of crop situations can be described. Crop photosynthesis was computed either from a given time course of radiation or from the daily total of radiation.

\section{METHODS}

\section{Diffuse and direct light}

The fraction of diffuse global radiation $\left(400-3000 \mathrm{~nm}, \mathrm{~W} \mathrm{~m}^{-2}\right)$ at any time of the day was calculated on the basis of the ratio between actual global radiation and extra-terrestrial radiation (Spitters et al., 1986). Generation of the diurnal course of total, direct and diffuse global radiation from the daily global radiation was also carried out as described by Spitters et al. (1986). Calcula- 
tion of the extra-terrestrial radiation and solar position was based on data of latitude, day of year and hour of the day. Photosynthetically active radiation (PAR, $400-700 \mathrm{~nm}$ ) was assumed to be $50 \%$ of global radiation.

\section{Geometry}

The rows of the crops were assumed to be hedgerows, i.e., they had a rectangular cross-section, called here the $x z$-plane, and were continuous in the longitudinal direction (the $y$ direction). The coordinate system as described by Goudriaan (1977, Chapter 2.4.4) was adopted here (Fig. 1). In this coordinate system $\alpha_{\mathrm{c}}$ and $\beta_{\mathrm{c}}$ can be computed by

$\sin \beta=\cos \alpha_{\mathrm{c}} \cos \beta_{\mathrm{c}}$

$\sin \beta_{\mathrm{c}}=\cos \alpha \cos \beta$

where $\beta$ is the angle of the light beam with the horizontal, $\beta_{\mathrm{c}}$ the angle with the $x z$-plane, $\alpha$ the difference between row azimuth (angle of row direction with north-south direction) and beam azimuth, and $\alpha_{\mathrm{c}}$ the angle of tilt of the plane through the light beam and $y$-axis.

The length of the horizontal component in the $x z$-plane (Fig. 2) is equal to

$x_{\text {hor }}=z \tan \alpha_{\mathrm{c}}$

where $z$ is the distance to the top of the row. A residual term, $x_{\mathrm{r}}$, is equal to the remainder of the total distance $x+x_{\text {hor }}$ minus the largest whole number of units (path + row)

$x_{\mathrm{r}}=\left|\left(\left(x_{\text {hor }}+x\right) /\left(W_{\mathrm{p}}+W_{\mathrm{r}}\right)\right)\right|$

where $W_{\mathrm{p}}$ and $W_{\mathrm{r}}$ are the widths of the path and the row, respectively, and $x$ is

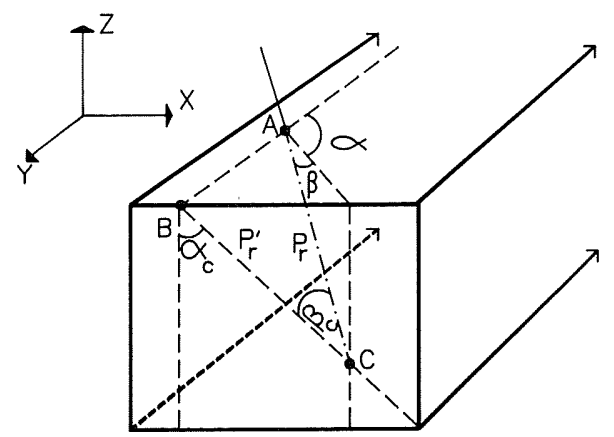

Fig. 1. The coordinate system used for geometrical calculations. AC is the length of the path of the light beam $\left(P_{\mathrm{r}}\right), \mathrm{BC}$ is the length of the component of $P$ in the $x z$-plane $\left(P^{\prime}{ }_{\mathrm{r}}\right), \alpha$ is the difference between row azimuth and beam azimuth, $\beta$ the angle of the beam with the horizontal (inclination), $\alpha_{\mathrm{c}}$ the angle of tilt of the plane through the light beam and $y$-axis and $\beta_{\mathrm{c}}$ the converted inclination. 


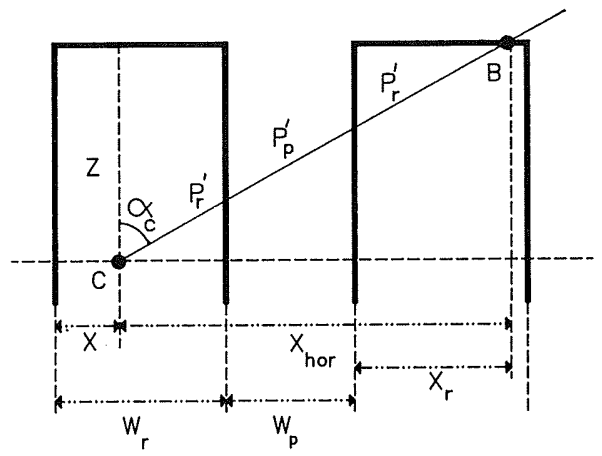

Fig. 2. Schematization of the calculation of the length of the component $P^{\prime}{ }_{\mathrm{r}}$ of the light beam in the $x z$-plane. See also Fig. 1 and the text.

the distance from the left side of the row. The integer number of units of (path + row) traversed $\left(N_{\mathrm{u}}\right)$ is equal to

$N_{\mathrm{u}}=\left(x_{\text {hor }}+x-x_{\mathrm{r}}\right) /\left(W_{\mathrm{p}}+W_{\mathrm{r}}\right)$

Then the path length through the rows only $\left(P^{\prime}{ }_{r}\right.$, Fig. 2$)$ is equal to, for $x_{\mathrm{r}} \leqslant W_{\mathrm{r}}$

$P^{\prime}{ }_{\mathrm{r}}=\left(N_{\mathrm{u}} W_{\mathrm{r}}-x+x_{\mathrm{r}}\right) / \sin \alpha_{\mathrm{c}}$

and for $x_{\mathrm{r}}>W_{\mathrm{r}}$

$P^{\prime}{ }_{\mathrm{r}}=\left[\left(N_{\mathrm{u}}+1\right) W_{\mathrm{r}}-x\right] / \sin \alpha_{\mathrm{c}}$

For generalization outside the $x z$-plane, the values of $P_{\mathrm{r}}^{\prime}$ must be divided by $\cos \beta_{\mathrm{c}}$

$P_{\mathrm{r}}=P^{\prime}{ }_{\mathrm{r}} / \cos \beta_{\mathrm{c}}$

The leaf area traversed by the beam is thus equal to

$L_{\mathrm{t}}=P_{\mathrm{r}} L_{\mathrm{d}}$

where $L_{\mathrm{d}}$ is the leaf area density $\left(\mathrm{m}^{2} \mathrm{~m}^{-3}\right)$ of a row with uniform leaf area density distribution. For a non-uniform distribution, $L_{t}$ is the sum of the leaf area densities of the canopy layers traversed by the light beam.

The distribution of the light absorption in the row crop is only determined by the relative dimensions of the rows. Therefore, in the simulation results the row width will be expressed as a ratio to row spacing, and is called the relative row cover. The row height will be expressed as a ratio to the row spacing. The leaf area index ( $L A I)$ of the crop is equal to the one-sided surface area of the leaves divided by the total ground area (row plus path). Therefore, decreasing the relative row cover with constant $L A I$ increases the leaf area density within the rows and also the $L A I$ expressed per row area. 
Attenuation of light

The attenuation of a single beam by black, i.e., non-transmitting and nonreflecting leaves, was computed according to Beer's law with

$I=I_{\mathrm{o}} \exp \left(-O_{\mathrm{av}} L_{\mathrm{t}}\right) / \sin \beta$

where $I$ is the light intensity in the plane normal to the light beam at point $(x, z)$ in the row, $I_{\mathrm{o}}$ the intensity above the canopy on a horizontal surface, $O_{\mathrm{av}}$ the average projection of the leaves into the direction of the beam and $L_{t}$ the leaf area traversed by the ray. The division by $\sin \beta$ is necessary to obtain the intensity in a plane normal to the beam. The average projection, $O_{\mathrm{av}}$, of the leaves with a spherical leaf angle distribution is 0.5 in every direction of the light. For horizontal leaves, this projection equals the sine of the angle of the beam with the horizontal $(\beta)$. For other leaf angle distributions, the average projection in a certain direction was calculated following the procedure given by Goudriaan (1988). In this procedure, the average projection was calculated with approximating formulae from the relative frequencies of the leaf inclination in the classes $0-30,30-60$ and $60-90^{\circ}$. No azimuthal preference of the leaves was assumed.

\section{Scattering}

The attenuation of light by scattering leaves is less than by black leaves. It was assumed that the fractions of light that are reflected and transmitted by a single leaf are equal (Gates et al., 1965; Woolley, 1971). The sum of these fractions is called the scattering coefficient $\sigma$ and for an average thin leaf is equal to $\sim 0.2$ (Gates et al., 1965; Woolley, 1971). The extinction coefficient of direct light in a horizontally homogeneous canopy for scattering horizontal leaves was obtained by multiplying the extinction coefficient for black horizontal leaves by $(1-\sigma)^{1 / 2}$ (Cowan, 1968; Goudriaan, 1977)

$K_{\text {dir,h }}=K_{\text {dir,h,bl }}(1-\sigma)^{1 / 2}$

where $K_{\mathrm{dir}, \mathrm{h}, \mathrm{bl}}$ is the extinction coefficient for black horizontal leaves. Thus for a horizontally homogeneous canopy, the light intensity on the horizontal plane at a point in a canopy with scattering leaves is calculated as

$I_{\mathrm{h}, \mathrm{dir}}=I_{\mathrm{o}} \exp \left[-K_{\mathrm{dir}, \mathrm{h}, \mathrm{bl}}(1-\sigma)^{1 / 2} L\right]$

where $L$ is the partial $L A I$ above the point. For other leaf angle distributions, scattering can be appropriately described by multiplying the extinction coefficient for black leaves by the same scattering factor $(1-\sigma)^{1 / 2}$ (Goudriaan, 1977), thus

$K_{\text {dir }}=K_{\text {dir,bl }}(1-\sigma)^{1 / 2}$ 
where $K_{\mathrm{dir}, \mathrm{bl}}=O_{\mathrm{av}} / \sin \beta$

The division by $\sin \beta$ accounts for the increased path length for paths other than vertical.

Reflection by the canopy

The reflection coefficient for horizontal leaves in a closed canopy is

$\rho_{\text {hor }}=\left[1-(1-\sigma)^{1 / 2}\right] /\left[1+(1-\sigma)^{1 / 2}\right]$

for every direction of the light beam (Cowan, 1968; Goudriaan, 1977). For a spherical leaf angle distribution, the reflection coefficient can be approximated by

$\rho_{\text {sph }}=\rho_{\text {hor }} \times 2 /(1+2 \sin \beta)$

where $\rho_{\mathrm{sph}}$ is the reflection coefficient for spherical leaves and $\beta$ the angle of the beam with the horizontal (Goudriaan, 1988). For the row crop model, it was assumed that the reflection coefficient for any leaf angle distribution is the same for light beams entering from the top of the row as for beams entering from the sides. On average, $6 \%$ of the light is reflected.

Intensity and absorption of diffuse light

The net flux of radiation through a horizontal plane $\left(I_{\mathrm{h}, \mathrm{dif}}\right)$ at point $(x, z)$ is given by

$I_{\mathrm{h}, \mathrm{dif}}=I_{0, \text { dif }} \frac{1}{\pi} \int_{-\pi 2}^{\pi / 2} \int_{-\pi / 2}^{\pi / 2}(1-\rho) \exp \left[-O_{\mathrm{av}} L_{\mathrm{t}}(1-\sigma)^{1 / 2}\right] \sin \beta \cos \beta_{\mathrm{c}} \mathrm{d} \beta_{\mathrm{c}} \mathrm{d} \alpha_{\mathrm{c}}$

where $I_{0, \text { dif }}$ is the incoming flux above the canopy and $O_{\mathrm{av}}$ the average projection of the leaves into the direction of the ray.

For each direction $\left(\beta_{\mathrm{c}}, \alpha_{\mathrm{c}}\right)$ separately, the rate of absorption by leaves at a given point in the canopy is equal to the rate of decrease in the direction of the flux

$$
\begin{aligned}
\frac{\mathrm{d} I}{\mathrm{~d} L_{\mathrm{t}}} & =I_{0} \mathrm{~d}\left\{\left\{\exp \left[-O_{\mathrm{av}} L_{\mathrm{t}}(1-\sigma)^{1 / 2}\right]\right\} / \sin \beta\right\} / \mathrm{d} L_{\mathrm{t}} \\
& =-I_{0} O_{\mathrm{av}}(1-\sigma)^{1 / 2} \exp \left[-O_{\mathrm{av}} L_{\mathrm{t}}(1-\sigma)^{1 / 2}\right] / \sin \beta
\end{aligned}
$$

Then, taking into account scattering and reflection, the absorbed flux of diffuse light was calculated as 


$$
\begin{aligned}
I_{\text {dif }}= & I_{0, \text { dif }} \frac{1}{\pi} \int_{-\pi / 2}^{\pi / 2} \int_{-\pi / 2}^{\pi / 2}(1-\rho) O_{\mathrm{av}}(1-\sigma)^{1 / 2} \\
& \exp \left[-O_{\mathrm{av}} L_{\mathrm{t}}(1-\sigma)^{1 / 2}\right] \cos \beta_{\mathrm{c}} \mathrm{d} \beta_{\mathrm{c}} \mathrm{d} \alpha_{\mathrm{c}}
\end{aligned}
$$

where $I_{0, \text { dif }}$ is the flux of diffuse light at the top of the canopy. Note that for black horizontal leaves, the absorbed diffuse light flux is equal to the light flux on the horizontal plane.

Integration was done by calculating the path lengths, attenuations and absorptions of the beams coming from every direction of the hemisphere. The number of calculations could be much reduced by applying the Gaussian integration principle (Goudriaan, 1986) to the integration over angles of incidence in eq. 19.

The use of a 3-point Gaussian integration requires a smooth curve without sharp bends within the integration interval. To fulfil this requirement, integration was done over segments whose limits were defined by the lines joining the point $(x, z)$ to the corners of the row (Fig. 3). In this way, the sharp bends in the curve of the response of absorption to angle of incidence were used as interval boundaries.

The numerical problems that occurred at very small row widths were solved by a special model version in which the limit transitions for this situation were taken into account.

\section{Intensity and absorption of direct light}

The calculation of the absorption and scattering of direct light followed the same lines of reasoning as the procedures given by Goudriaan $(1977,1982)$ and Spitters (1986) for horizontally homogeneous canopies.

\section{Leaf $\mathrm{CO}_{2}$ assimilation}

The gross assimilation rate at a given point was calculated using the photosynthesis-light response curve of individual leaves. The curve used here was

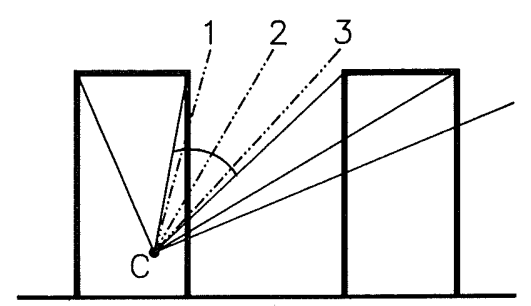

Fig. 3. The delimitation of segments for integration of diffuse light at point $(x, z)$. In each segment, three selected angles of incidence can be chosen for 3-point Gaussian integration. 
an asymptotic exponential curve, characterized by the initial light use efficiency $\left(\epsilon, \mathrm{mg} \mathrm{CO}_{2} \mathrm{~J}^{-1}\right.$ PAR absorbed) and the gross photosynthetic rate at light saturation $\left(A_{\mathrm{m}}, \mathrm{mg} \mathrm{CO}_{2} \mathrm{~m}^{-2} \mathrm{~s}^{-1}\right)$

$A=A_{\mathrm{m}}\left[1-\exp \left(-\epsilon I_{\mathrm{a}} / A_{\mathrm{m}}\right)\right]$

where $I_{\mathrm{a}}$ is the absorbed light flux. The values used in the simulation runs were $0.011 \mathrm{mg} \mathrm{CO}_{2} \mathrm{~J}^{-1}$ PAR for efficiency and $0.91 \mathrm{mg} \mathrm{CO}_{2} \mathrm{~m}^{-2} \mathrm{~s}^{-1}$ for the rate of gross photosynthesis at light saturation. These values are typical for $\mathrm{C}_{3}$ plants under the normal $\mathrm{CO}_{2}$ content of air.

To find the total gross leaf assimilation rate at a certain point $(x, z), A_{\mathrm{sh}}$ and $A_{\mathrm{sl}}$ must be multiplied by the fraction of sunlit $\left(F_{\mathrm{sl}}\right)$ and shaded $\left(1-F_{\mathrm{sl}}\right)$ leaf area at that point, respectively

$A=A_{\mathrm{sh}}\left(1-F_{\mathrm{sl}}\right)+A_{\mathrm{s}} F_{\mathrm{sl}}$

\section{Integration of assimilation over row height and width}

To find the total gross assimilation rate of the row, assimilation rates can, for instance, be calculated at a $10 \times 10$ grid and summed. A method which reduces the computational load is to integrate with a 5-point Gaussian integration, both horizontally and vertically in the row. Then the assimilation rates need to be computed only at the 25 points of the $5 \times 5$ grid.

The points $\left(x_{i}, z_{j}\right)$ in the $x z$-plane were selected according to

$x_{i}=\left(0.5+\Delta x_{i}\right) W_{\mathrm{r}}$ and

$z_{j}=\left(0.5+\Delta z_{j}\right) H_{\mathrm{r}}$

where $H_{\mathrm{r}}$ is the height of the row, and $\Delta x_{i}$ and $\Delta z_{j}$ are $-0.453090,-0.269235$, $0.0,0.269235$ and 0.453090 for $i$ or $j=1-5$. The weight to be given to the rate of leaf photosynthesis at the selected points are, for $i$ or $j$ at 1 or $5,0.118463$, for $i$ or $j$ at 2 and $4,0.239314$, and for $i$ or $j$ at $3,0.284444$.

The 5-point Gaussian integration of the rate of leaf photosynthesis proved to have a satisfactory accuracy. When evaluated for a range of $L A I \mathrm{~s}$, row geometries and various dates in the year, the calculated rate of crop photosynthesis deviated for most situations by $<0.5 \%$ from the rate of photosynthesis calculated with a $40 \times 40$ grid in the row. With a few exceptions, it always performed better than integration with a $10 \times 10$ grid.

\section{Diurnal and daily photosynthesis}

The effect of the row structure on diurnal and daily gross photosynthesis was studied by simulating the diurnal course of the fluxes of total, direct and diffuse radiation $\left(\mathrm{W} \mathrm{m}^{-2}\right.$ ) for 21 March at various latitudes. At this date, 
sunrise occurs at exactly $6 \mathrm{~h}$ solar time. The diurnal courses on days with 50 and $75 \%$ direct radiation in the daily total were generated using both the relation of daily fraction of diffuse global radiation versus atmospheric transmission, and the average diurnal trend of the atmospheric transmission for de Bilt, The Netherlands, as given by Spitters et al. (1986).

\section{The effect of soil albedo on photosynthesis}

The effect of light reflected by the soil surface was calculated in two steps. In the first step, the light intensity distribution on the soil surface was calculated. In the second step, the contribution of this source to the radiation absorption at any point in the row was calculated in the same way as described for diffuse radiation incoming from above.

\section{Validation measurements}

The calculation of the diffuse light interception was validated for a young maize crop with distinct rows $(L A I=2.0)$. Row transects were approximately shaped like upside-down triangles with base length $0.65 \mathrm{~m}$ and height $0.8 \mathrm{~m}$, with their lower tips touching the soil surface. The row spacing was $0.75 \mathrm{~m}$. PAR was measured with a point meter (Type 53066, Technical and Physical Service for Agriculture, Wageningen) at $\sim 2 \mathrm{~cm}$ above the soil.

\section{RESULTS}

Unless otherwise stated, the leaf angle distribution was assumed to be spherical and the vertical leaf area density distribution homogeneous.

\section{Absorption and photosynthesis}

Absorption of diffuse light by a row crop with a height/distance ratio of unity was not much reduced compared with a closed crop canopy as long as the relative row cover is $>75 \%$ (Fig. 4, Table 1 ). For a relative row cover of $50 \%$, the reduction compared with a closed canopy was significant and ranges from 6 to $13 \%$ for $L A I=1$ and 3 , respectively, at a ratio of height/row spacing of 1 , and from 16 to $29 \%$ at a ratio of 0.25 . Absorption was practically independent of the presence of paths when the ratio of height/row spacing was high enough. Below a row cover of $<5 \%$, integration of absorption over the row became inaccurate. The absorption at the hypothetical zero relative row cover, as calculated with an adapted version of the model, was only slightly less than at $5 \%$ row cover.

The calculated distribution of light absorption for a row crop at $L A I=3$ is 
10
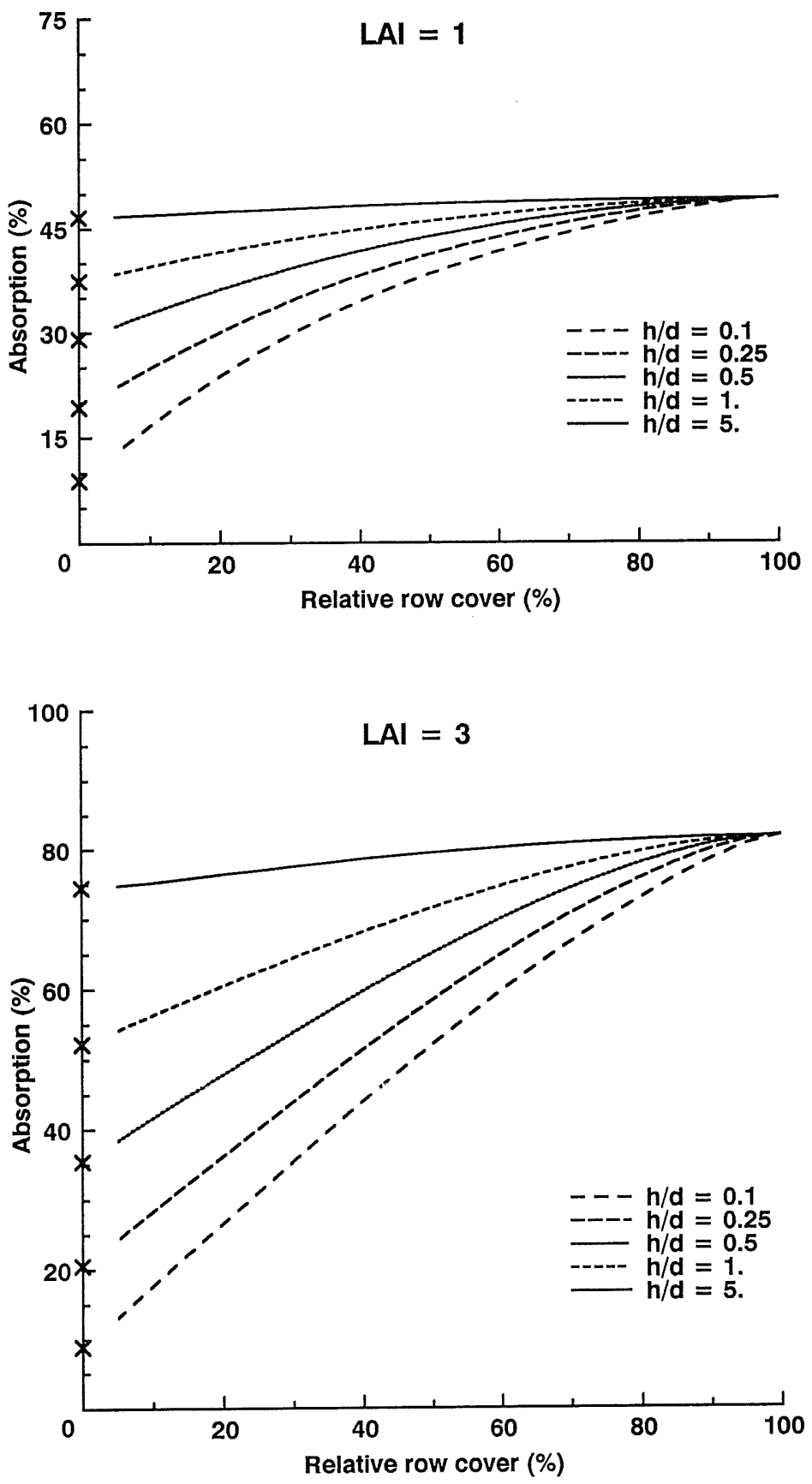

Fig. 4. The influence of the relative row cover on the absorption (\%) of diffuse incoming light by a row crop with $L A I=1$ and 3. $h=$ row height, $d=$ row spacing. Crosses on the $y$-axis mark absorption values as calculated with the adapted version of the model. 


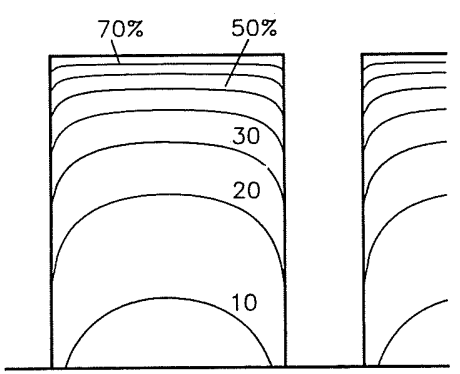

A
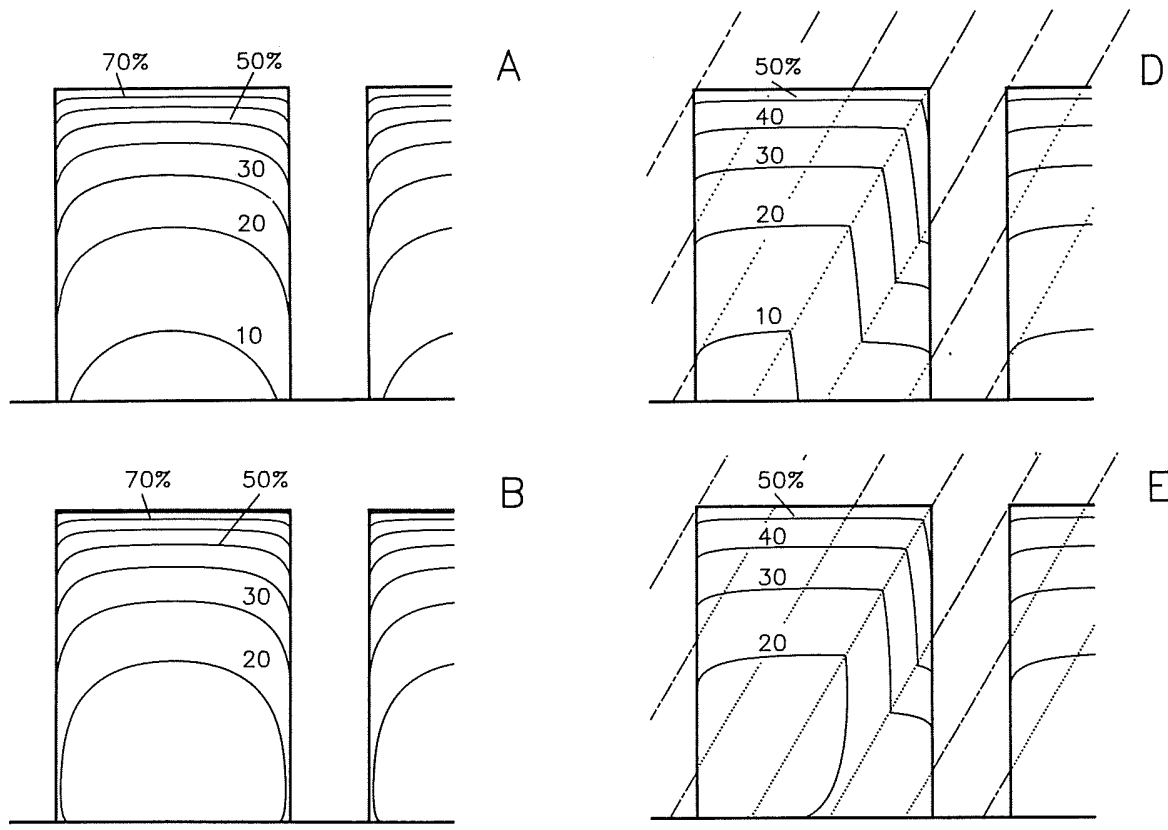

B

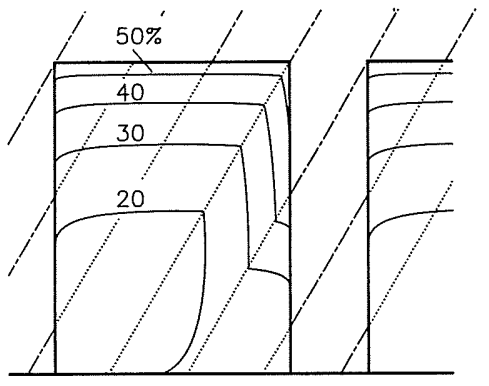

$E$

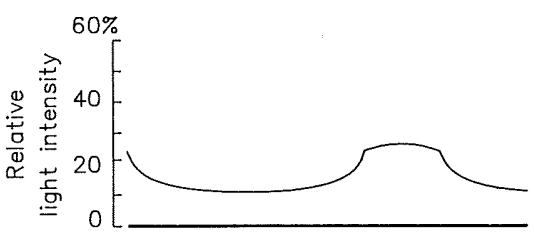

C

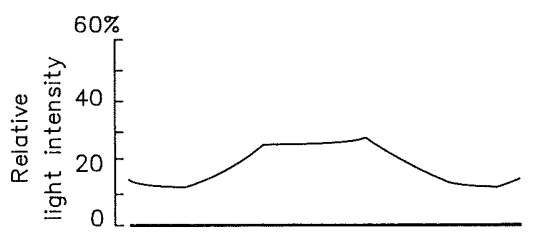

Fig. 5. The absorbed light intensity per unit leaf area in the row as a percentage of incident light above the canopy for a row crop at $L A I=3$, at a ratio of row height to row spacing of 1 and at $75 \%$ relative row cover. (a) $100 \%$ diffuse light; (b) $100 \%$ diffuse light and with ground reflection of 0.4; (c) light intensity per $\mathrm{m}^{2}$ soil surface relative to the light intensity on the horizontal above the canopy; $\left(\mathrm{d}\right.$, e and $\mathrm{f}$ ) identical but for $80 \%$ direct light, solar elevation $60^{\circ}$, difference between sun and row azimuth $90^{\circ}$.

depicted in Fig. 5. Near the bottom of the rows, the edge effect was larger than near the top, and was enhanced by reflection by the ground surface. Even at the top of the canopy, the absorption of light per leaf area was $<100 \%$ because of reflection and transmission, and because even for black leaves the extinction coefficient for direct and diffuse light was less than unity.

Scattering of light significantly reduced the calculated light absorption and rate of photosynthesis (Fig. 6). The effect on photosynthesis was less than on absorption as increased scattering gives a more equal distribution of light in the rows. The dependence of canopy photosynthesis on row cover was little influenced by radiation level, with row effect slightly decreasing with increasing radiation level (Table 1 ). 

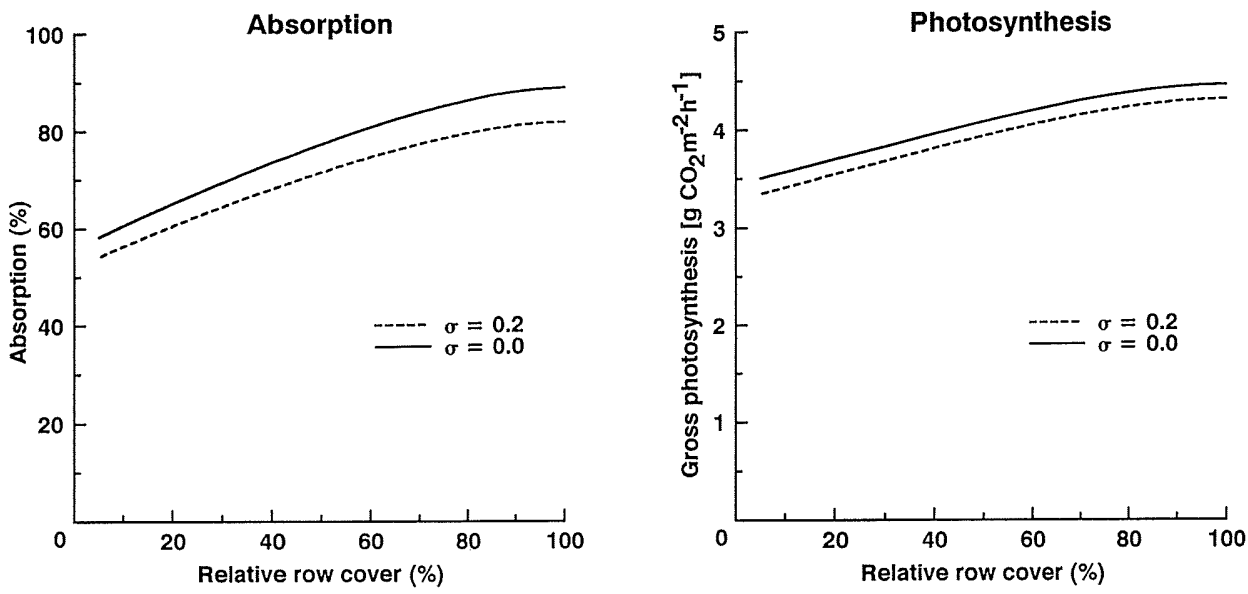

Fig. 6. The influence of the relative row cover (\%) on the absorption $(\%)$ and the rate of gross photosynthesis $\left(\mathrm{g} \mathrm{CO}_{2} \mathrm{~m}^{-2} \mathrm{~h}^{-1}\right)$ of a row crop with $L A I=3$ and with a scattering coefficient $(\sigma)$ of 0 or 0.2 under diffuse light $\left(200 \mathrm{~W} \mathrm{~m}^{-2}\right)$. The ratio of row height to row spacing is 1 .

\section{TABLE 1}

The absorption and rate of gross photosynthesis of a row crop under diffuse light expressed as a percentage of that of a crop with a horizontally homogeneous canopy, for $L A I=1$ and 3, relative row covers of 50 and $75 \%$, and ratios of row height to row distance of 0.25 and 1

\begin{tabular}{|c|c|c|c|c|c|}
\hline \multirow[t]{3}{*}{$L A I$} & \multirow[t]{3}{*}{ Crop response } & \multicolumn{4}{|c|}{ Relative row cover $(\%)$} \\
\hline & & \multicolumn{2}{|l|}{50} & \multicolumn{2}{|l|}{75} \\
\hline & & $h / d=0.25^{\mathrm{a}}$ & $h / d=1$ & $h / d=0.25$ & $h / d=1$ \\
\hline \multirow[t]{3}{*}{1} & Absorption & 84 & 94 & 95 & 98 \\
\hline & Photosynthesis $(100)^{b}$ & 87 & 95 & 97 & 99 \\
\hline & $(200)$ & 89 & 96 & 97 & 99 \\
\hline \multirow[t]{3}{*}{3} & Absorption & 71 & 87 & 89 & 96 \\
\hline & Photosynthesis (100) & 73 & 90 & 90 & 97 \\
\hline & $(200)$ & 75 & 91 & 91 & 97 \\
\hline
\end{tabular}

${ }^{\mathrm{a}} h=$ row height; $d=$ row spacing. ${ }^{\mathrm{b}}$ Relative rate of gross photosynthesis under 100 or $200 \mathrm{~W} \mathrm{~m}^{-2}$ (PAR).

The influence of the vertical distribution of leaf area density on the rate of photosynthesis at diffuse light was small (Fig. 7). A uniform distribution appeared to be the most favourable, and a leaf area density that decreases from the top of the rows to the bottom was slightly better than the two other leaf area distributions. 


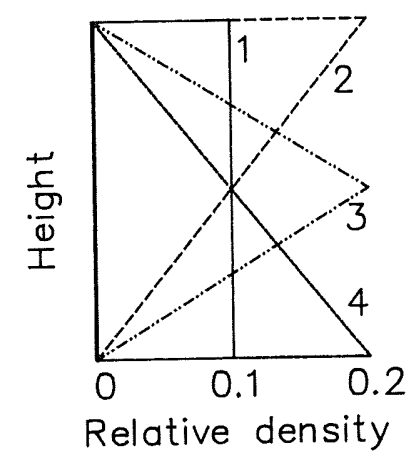

A

B

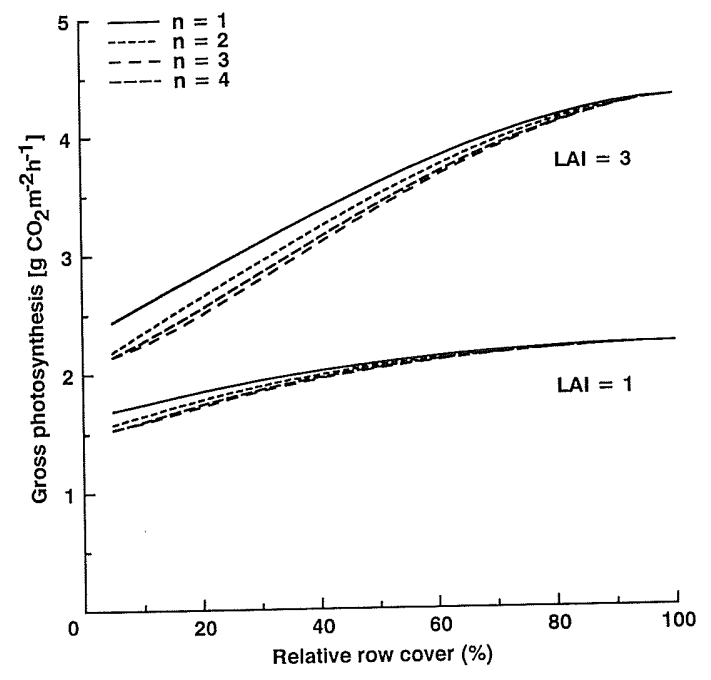

Fig. 7. The rate of gross photosynthesis $\left(\mathrm{g} \mathrm{CO}_{2} \mathrm{~m}^{-2} \mathrm{~h}^{-1}\right)$ at diffuse light $\left(200 \mathrm{~W} \mathrm{~m}^{-2}\right)$ of a row crop for four vertical leaf area density distributions $(n)$. The ratio of row height to row spacing is 0.5. (a) Depiction of the four different leaf area density distributions. (b) The influence of the relative row cover on the rate of photosynthesis at $L A I=1$ or 3 .

The effect of increasing soil albedo from 0 to 0.4 on row crop photosynthesis is shown in Fig. 8. The value of 0.4 is typical for plastics that are used as a ground cover in greenhouses. The effect was significant and was somewhat larger for a row crop than for a closed canopy crop. For relative row covers of $>65 \%$, the rate of photosynthesis was even higher than that of a closed canopy crop. 


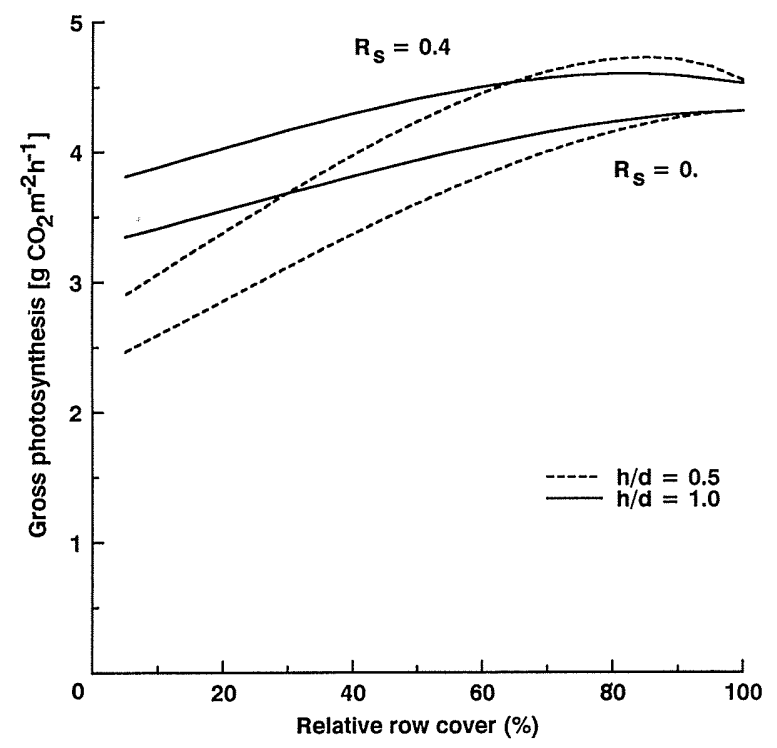

Fig. 8. The influence of a soil reflection $\left(R_{\mathrm{s}}\right)$ of 0.4 and the relative row cover on the rate of gross photosynthesis $\left(\mathrm{g} \mathrm{CO}_{2} \mathrm{~m}^{-2} \mathrm{~h}^{-1}\right)$ of a row crop with $L A I=3$ and with a ratio of row height to row spacing of 0.5 or $1 . h=$ row height; $d=$ row spacing.

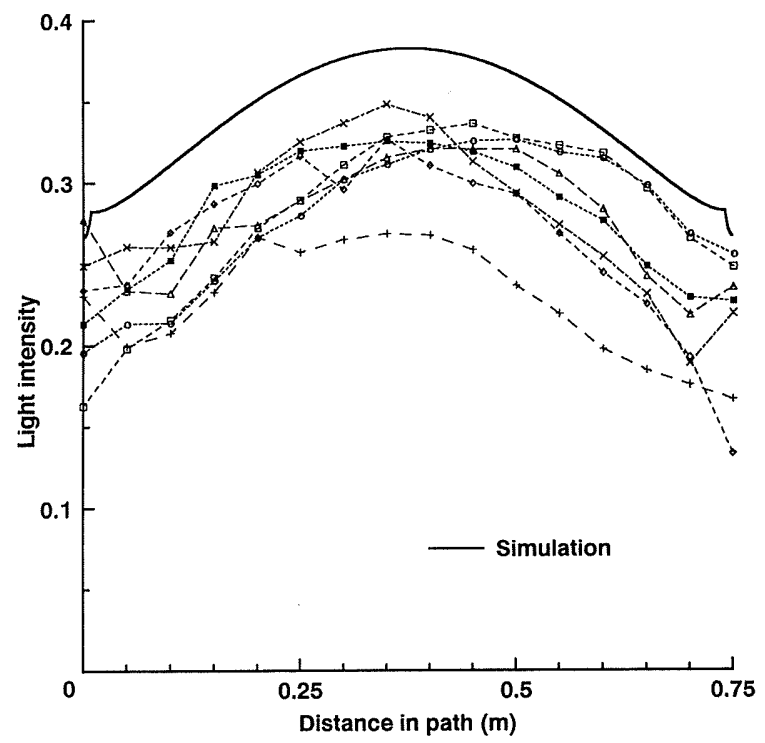

Fig. 9. The measured and simulated light intensity on the horizontal under a young maize crop $(L A I=2.0)$ as a fraction of that above the canopy, at $100 \%$ diffuse light. Row transects are upsidedown triangles (base of triangle $0.65 \mathrm{~m}$, height $0.8 \mathrm{~m}$ ) touching the soil surface at a spacing of 0.75 $\mathrm{m}$. The plane of measurement intersects the rows at $2 \mathrm{~cm}$ above the soil. Lines connecting symbols indicate seven replications of light measurement along the path transect. Each replication consisted of consecutive measurements at 5 -cm intervals. 


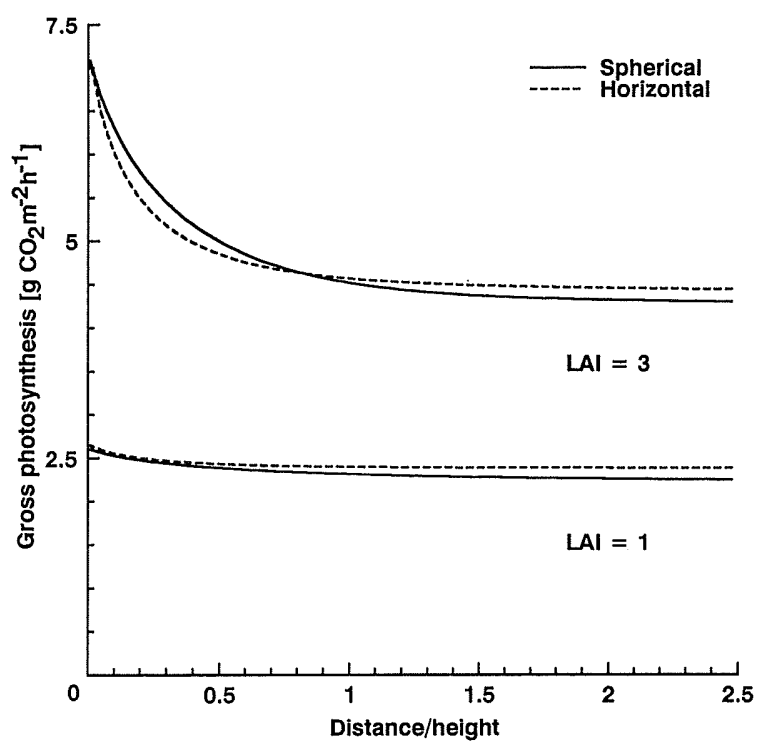

Fig. 10. The edge effect of photosynthesis dependent on the distance to the edge of an otherwise horizontally infinitely large crop. The rate of gross photosynthesis $\left(\mathrm{g} \mathrm{CO}_{2} \mathrm{~m}^{-2} \mathrm{~h}^{-1}\right)$ is totalled over the entire height of the crop. The distance is expressed as the ratio of distance to the crop edge versus crop height.

\section{Validation}

For simulation, a standard overcast sky was assumed with luminance at the zenith three times as large as the luminance at the horizon. The model was adapted to account for the triangular geometry of this crop. Simulation of the light intensity on the soil surface beneath a young maize crop overestimated measured light intensities by $\sim 5 \%$ (Fig. 9). The crop appeared to intercept light somewhat more effectively than calculated. However, the shape of the interception curve is well simulated. The two dips at either end of the simulated curve are caused by the simulated downward pointing tip of the row triangles.

\section{Edge effect in an otherwise homogeneous canopy}

By taking the path width very large and the row height small compared with the row distance, the edge of a homogeneous field crop can be simulated. The edge effect on photosynthesis can be shown by the rate of gross photosynthesis per ground area as a function of the distance from the edge (Fig. 10). At a distance from the edge equal to the height of the crop, the edge effect had practically disappeared. At low $L A I$, the edge effect was even smaller. The edge effect in a canopy with horizontal leaves extended less far than in a canopy with a spherical leaf angle distribution. 

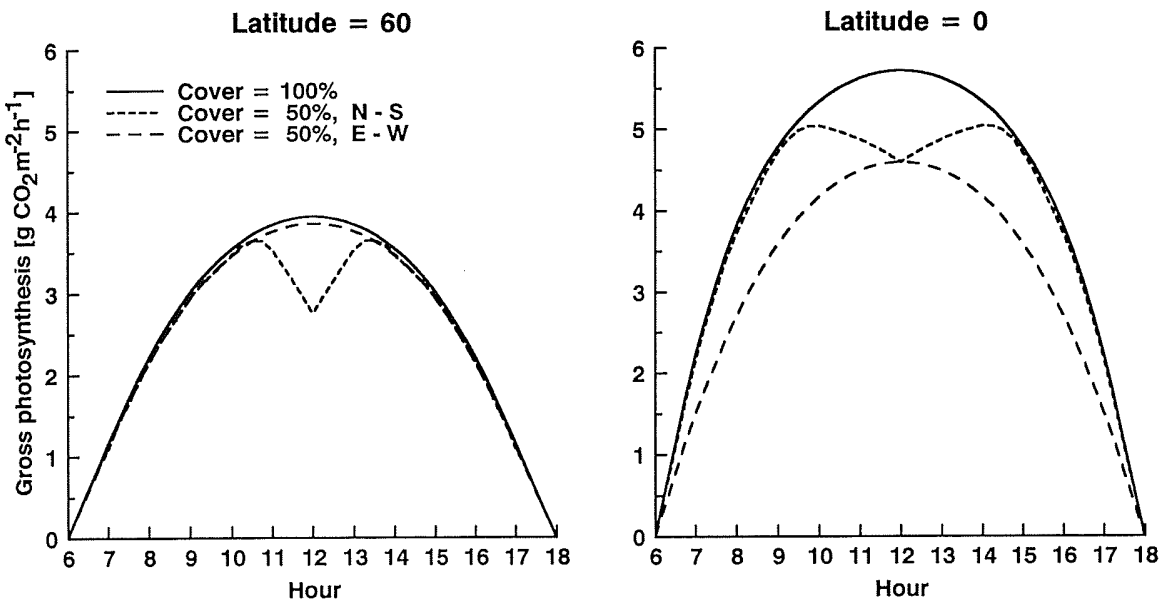

Fig. 11. The diurnal rate of gross photosynthesis $\left(\mathrm{g} \mathrm{CO}_{2} \mathrm{~m}^{-2} \mathrm{~h}^{-1}\right)$ of a row crop with $L A I=2.5$, a ratio of row height to row spacing of 1 , relative row covers of 50 and $100 \%$, row orientations northsouth and east-west and latitudes 0 and $60^{\circ}$. Direct radiation is $75 \%$ of the daily total.

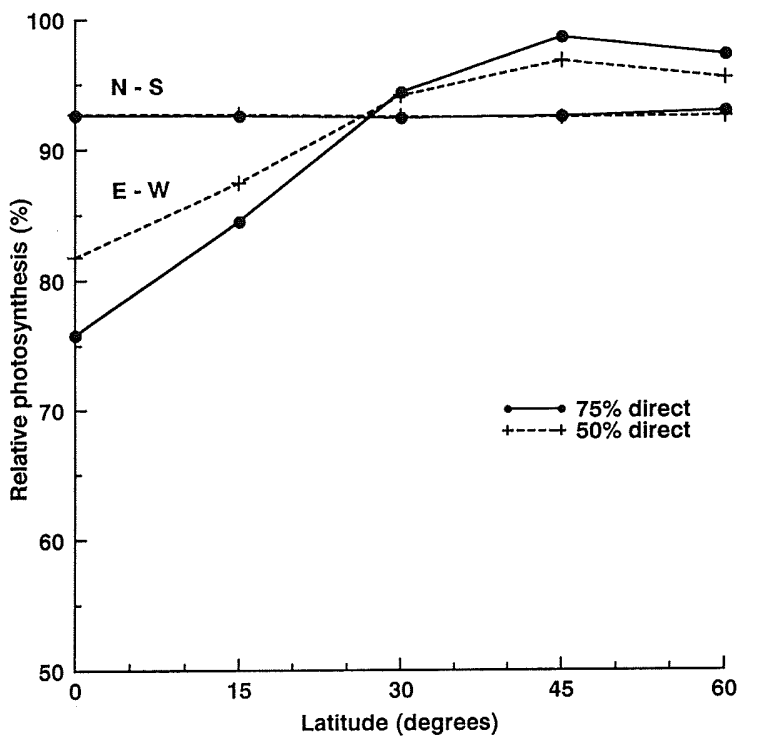

Fig. 12. The daily photosynthesis of a row crop at relative row cover of $50 \%$ as a percentage of that of a horizontally homogeneous canopy, at $21 \mathrm{March}$, for various latitudes, and for 75 and $50 \%$ direct radiation in the daily total. The $L A I=2.5$ and the ratio of row height to row spacing is 1.

\section{Diurnal and daily photosynthesis}

The diurnal rate of gross photosynthesis at 21 March at latitudes 0 and $60^{\circ}$ for days with $75 \%$ direct radiation in the daily total is shown in Fig. 11. For a 
crop with rows oriented north-south, a significant depression in the rate of gross photosynthesis at midday hours occurred, dependent on the relative row cover. For rows oriented east-west, the reduction in potential photosynthesis with decreasing row cover was considerably dependent on the latitude, i.e., the solar elevation during most of the day.

Daily photosynthesis of a north-south-oriented crop, relative to the daily photosynthesis of a horizontally homogeneous canopy, was little sensitive to the fraction of direct radiation for 21 March (Fig. 12). With $2 \%$ direct radiation in the daily total, the relative daily photosynthesis was only $2 \%$ lower than at $75 \%$ direct radiation. Also, for a crop with $L A I=1$ the loss of potential photosynthesis hardly varied with different fractions of direct light (not shown). For row crops oriented east-west, the relative daily photosynthesis increased with latitude from 0 to $60^{\circ}$. At $27^{\circ}$ latitude, the curves crossed over, so that in the tropics a north-south orientation gave a higher photosynthesis and in the temperate zone an east-west orientation.

\section{DISCUSSION}

Simulation results indicated that the row structure caused only a small loss of radiation absorption and of photosynthesis under diffuse light for ratios of path width over row height $<0.3$. The loss of photosynthesis under diffuse light was generally less for increasing ratios of row height to row spacing, not only because of less loss of light to the ground, but also because of a more even light distribution. For direct light, absorption and photosynthesis of row crops were little reduced compared with a horizontally homogeneous canopy for many possible positions of the sun in the sky. The effect of row structure on absorption and photosynthesis increased with $L A I$.

Calculations of relative daily photosynthesis for 21 March for various latitudes indicated that daily photosynthesis was especially dependent on the row direction in the tropics. For a crop with row direction east-west, loss of light to the path can occur during most of the day. At latitudes $30-50^{\circ}$, the row direction was not important. This was also calculated by Charles-Edwards and Thorpe (1976) for the amount of radiation absorbed by an orchard at Kew (U.K., latitude $52^{\circ}$ ) with a ratio of row height to row spacing of 0.36 and relative row cover 0.4 . In that case, about half of the daily total radiation was diffuse. For row direction north-south, the fraction of direct radiation in the daily total had surprisingly little influence on the daily photosynthesis expressed as a percentage of that of a closed canopy. It seems that the negative effect of less interception at midday hours with higher fractions of direct light is largely offset by the increased interception in the morning and in the afternoon.

In conclusion, the effect of the row structure on light interception and photosynthesis was small when the path width is in the order of $\leqslant 30 \%$ of the row height. Calculation of multiple scattering and reflection, and the separation of the light into diffuse and direct were important for an accurate estimation of 
the rate of row crop photosynthesis. At a soil reflection of 40\%, crop photosynthesis was significantly enhanced.

\section{APPENDIX: DEFINITION OF SYMBOLS}

A Rate of leaf gross assimilation at point $(x, z), \mathrm{mg} \mathrm{CO}_{2} \mathrm{~m}^{-2} \mathrm{~s}^{-1}$

$A_{\mathrm{m}} \quad$ Rate of leaf gross assimilation at light saturation, $\mathrm{mg} \mathrm{CO}_{2} \mathrm{~m}^{-2} \mathrm{~s}^{-1}$

$A_{\mathrm{sh}} \quad$ Rate of gross assimilation of shaded leaves (receiving diffuse light only), $\mathrm{mg} \mathrm{CO}_{2} \mathrm{~m}^{-2} \mathrm{~s}^{-1}$

$A_{\mathrm{sl}} \quad$ Rate of gross assimilation of sunlit leaves (receiving diffuse and direct light), $\mathrm{mg} \mathrm{CO}_{2} \mathrm{~m}^{-2} \mathrm{~s}^{-1}$

$F_{\mathrm{sl}} \quad$ Fraction of leaves that are sunlit at point $(x, z)$

$H_{\mathrm{r}} \quad$ Height of row, $\mathrm{m}$

I Intensity of light in a plane normal to beam direction, $\mathrm{J} \mathrm{m}^{-2} \mathrm{~s}^{-1}$

$I_{\mathrm{a}} \quad$ Intensity of total absorbed light (per leaf area), $\mathrm{J} \mathrm{m}^{-2} \mathrm{~s}^{-1}$

$I_{\text {dif }} \quad$ Intensity of absorbed diffuse light (per leaf area), $\mathrm{J} \mathrm{m}^{-2} \mathrm{~s}^{-1}$

$I_{\mathrm{h}, \text { dif }} \quad$ Intensity of diffuse light on the horizontal plane, $\mathrm{J} \mathrm{m}^{-2} \mathrm{~s}^{-1}$

$I_{\mathrm{h}, \mathrm{dir}} \quad$ Intensity of direct light on the horizontal plane, $\mathrm{J} \mathrm{m}^{-2} \mathrm{~s}^{-1}$

$I_{0} \quad$ Intensity of light beam above the canopy, $\mathrm{J} \mathrm{m}^{-2} \mathrm{~s}^{-1}$

$I_{0, \text { dif }} \quad$ Intensity of diffuse light above the canopy, $\mathrm{J} \mathrm{m}^{-2} \mathrm{~s}^{-1}$

$K_{\text {dir }} \quad$ Extinction coefficient for direct light

$K_{\text {dir,bl }} \quad$ Extinction coefficient for direct light of black leaves

$K_{\text {dir,hor }} \quad$ Extinction coefficient of horizontal leaves for direct light

$K_{\text {dir,hor,bl }} \quad$ Extinction coefficient of black horizontal leaves for direct light

$L A I \quad$ Leaf area index

$L_{\mathrm{d}} \quad$ Leaf area density, $\mathrm{m}^{2} \mathrm{~m}^{-3}$

$L_{\mathrm{t}} \quad$ Leaf area traversed by beam

$N_{\mathrm{u}} \quad$ Number of units $\left(W_{\mathrm{p}}+W_{\mathrm{r}}\right)$ traversed by beam

$O_{\mathrm{av}} \quad$ Average projection of the leaves into the direction of the beam

$P \quad$ Path length of beam through canopy, $\mathrm{m}$

$P_{\mathrm{r}} \quad$ Path length of beam through rows only, $\mathrm{m}$

$P^{\prime} \quad$ Path length of the component of the beam in the $x z$-plane through canopy, $\mathrm{m}$

$P_{\mathrm{p}}^{\prime} \quad$ Path length of the component of the beam in the $x z$-plane through the paths, $m$

$P^{\prime}{ }_{\mathrm{r}} \quad$ Path length of the component of the beam in the $x z$-plane through rows only, $\mathrm{m}$

$W_{\mathrm{p}} \quad$ Width of the path, $\mathrm{m}$

$W_{\mathrm{r}} \quad$ Width of the row, $\mathrm{m}$

$x \quad$ Lateral distance from side of row, $\mathrm{m}$

$z \quad$ Vertical distance from top of row, $\mathrm{m}$

$\alpha \quad$ Difference between row and beam azimuth, ${ }^{\circ}$

$\alpha_{\mathrm{c}} \quad$ Angle of tilt of plane through the $y$-axis and light beam, ${ }^{\circ}$ 


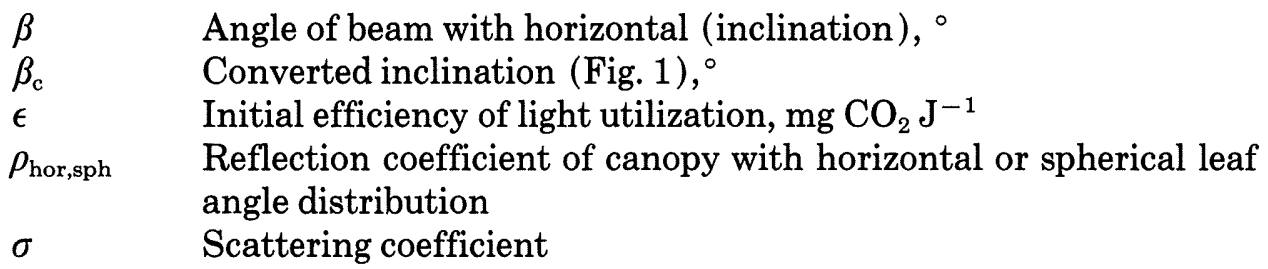

\section{REFERENCES}

Acock, B., Charles-Edwards, D.A., Fitter, D.J., Hand, D.W. and Warren Wilson, J., 1978. Modelling canopy net photosynthesis by isolated blocks and rows of chrysanthemum plants. Ann. Appl. Biol., 90: 255-263.

Allen, L.H., Jr., 1974. Model of light penetration into a wide-row crop. Agron. J., 66: 41-47.

Charles-Edwards, D.A. and Thorpe, M.R., 1976. Interception of diffuse and direct-beam radiation by an hedgerow apple orchard. Ann. Bot., 40: 603-613.

Cowan, I.R., 1968. The interception and absorption of radiation in plant stands. J. Appl. Ecol., 5: 367-379.

Gates, D.M., Keegan, H.J., Schleter, J.C. and Weidner, V.R., 1965. Spectral properties of plants. Appl. Optics, 4: 11-20.

Goudriaan, J., 1977. Crop micrometeorology: a simulation study. Simulation Monographs, PUDOC, Wageningen, $249 \mathrm{pp}$.

Goudriaan, J., 1982. Potential production processes. In: F.W.T. Penning de Vries and H.H. van Laar (Editors), Simulation of Plant Growth and Crop Production. Simulation Monographs, PUDOC, Wageningen, pp. 98-113.

Goudriaan, J., 1986. A simple and fast numerical method for the computation of daily totals of crop photosynthesis. Agric. For. Meteorol., 38: 251-255.

Goudriaan, J., 1988. The bare bones of leaf angle distribution in radiation models for canopy photosynthesis and energy exchange. Agric. For. Meteorol., 43: 155-170.

Jackson, J.E. and Palmer, J.W., 1979. A simple model of light transmission and interception by discontinuous canopies. Ann. Bot., 44: 381-383.

Jackson, J.E. and Palmer, J.W., 1981. Light distribution in discontinuous canopies: calculation of leaf areas and canopy volumes above defined "irradiance contours" for use in productivity modelling. Ann. Bot., 47: 561-565.

Mann, J.E., Curry, G.L., DeMichele, D.W. and Baker, D.N., 1980. Light penetration in a rowcrop with random plant spacing. Agron. J., 72: 131-142.

Mutsaers, H.J.W., 1980. The effect of row orientation; date and latitude on light absorption by row crops. J. Agric. Sci., 95: 381-386.

Norman, J.M. and Welles, J.M., 1983. Radiative transfer in an array of canopies. Agron. J., 75: 481-488.

Palmer, J.W., 1977. Diurnal light interception and a computer model of light interception by hedgerow apple orchards. J. Appl. Ecol., 14: 601-614.

Rabbinge, R., 1976. Biological control of fruit-tree red spider mite. Simulation Monographs, PUDOC, Wageningen, $228 \mathrm{pp}$.

Spitters, C.J.T., 1986. Separating the diffuse and direct component of global radiation and its implications for modeling canopy photosynthesis. Part II. Calculation of canopy photosynthesis. Agric. For. Meteorol., 38: 231-242. 
Spitters, C.J.T., Toussaint, H.A.M. and Goudriaan, J., 1986. Separating the diffuse and direct component of global radiation and its implications for modeling canopy photosynthesis. Part I. Components of incoming radiation. Agric. For. Meteorol., 28: 217-229.

Whitfield, D.M., 1986. A simple model of light penetration into row crops. Agric. For. Meteorol., 36: 297-315.

Woolley, J.T., 1971. Reflectance and transmittance of light by leaves. Plant Physiol., 47: 656-662. 